\title{
Necessity of tobramycin trough levels in once daily iv-treatment in patients with cystic fibrosis
}

\author{
Anne Schlegtendal ${ }^{1}$, Folke Brinkmann ${ }^{1}$, Sophia Rettberg ${ }^{1}$, Christoph Maier ${ }^{1}$, Tobias \\ Rothoeft $^{1}$, and Cordula Koerner-Rettberg ${ }^{2}$ \\ ${ }^{1}$ Bochum Saint Joseph's Hospital \\ ${ }^{2}$ Children's Hospital \& Research Institute, Marienhospital Wesel
}

October 10, 2020

\begin{abstract}
Background: Once daily intravenous (iv) treatment with tobramycin for Pseudomonas aeruginosa infection in patients with cystic fibrosis $(\mathrm{CF})$ is usually monitored by measuring tobramycin trough levels. Although the necessity of these trough levels is recently questioned in $\mathrm{CF}$ patients without renal impairment, no study has evaluated this so far. The aim of this observational study was to evaluate the frequency of increased tobramycin trough levels in 278 courses of iv tobramycin in CF children and adolescents. Methods: Patient records of all consecutive once daily iv tobramycin courses in 35 CF patients between $07 / 2009$ and 07/2019 were analyzed for tobramycin level, renal function, co-medication and comorbidity. Results: Eight elevated tobramycin levels ( $2.9 \%$ of 278 courses) were recorded in four patients, two with normal renal function. One of these did resolve without adjustment of tobramycin dosages suggesting laboratory error. In the other patient elevated tobramycin levels occurred after recently being started on lumacaftor/ivacaftor and decreased after dosage adjustment. Six of the elevated levels occurred in two patients with chronic renal failure. In 15 other patients with reduced glomerular filtration rate (GFR) (36 courses) no case of an elevated tobramycin trough level was detected. Cumulative tobramycin dosages were neither a risk factor for elevated trough levels nor were diabetes or nutritional status. Conclusion: In CF patients with normal GFR (GFR >100 ml/min) and in absence of additional risk factors (e.g. recently started CFTR modulator therapy) a monitoring of the once daily iv treatment by tobramycin trough levels seems not to be necessary.
\end{abstract}

\section{Hosted file}

Necessity of tobramycin trough levels in CF patients_main document.pdf available at https://authorea.com/users/366012/articles/485912-necessity-of-tobramycin-trough-levelsin-once-daily-iv-treatment-in-patients-with-cystic-fibrosis

\section{Hosted file}

Table 1-4.pdf available at https://authorea.com/users/366012/articles/485912-necessity-oftobramycin-trough-levels-in-once-daily-iv-treatment-in-patients-with-cystic-fibrosis 

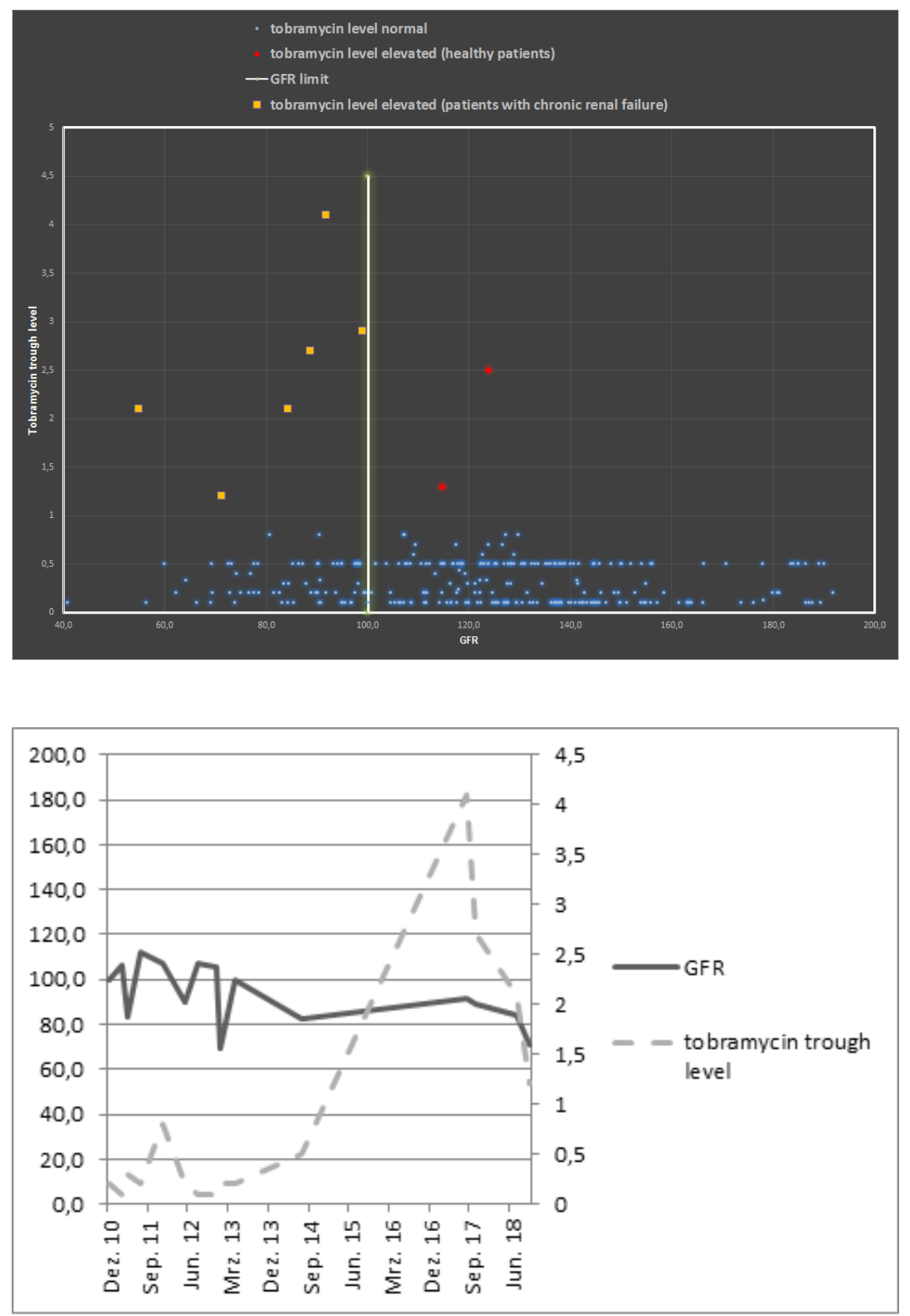